\title{
Delamination and Separation of Aluminum-Polyethylene-Paper Packing Material
}

\author{
Chongqing Wang, Qun Liu, Hui Wang*, Chengcheng Luo, Fangfang Jia and Xiangrui Meng
}

\author{
School of Chemistry and Chemical Engineering, Key Laboratory of Resources Chemistry of Nonferrous \\ Metals, Ministry of Education, Central South University, Changsha, 410083 Hunan, China
}

\begin{abstract}
Delamination and separation of laminated aluminum- polyethylene-paper packaging material were conducted for recycling packaging materials. Delamination was carried out using glacial acetic acid (GAA) solution. $L_{9}\left(3^{4}\right)$ orthogonal experiments demonstrate that the most significant factor is GAA concentration followed by temperature and liquid/solid ratio. The delamination time decreased sharply with increasing temperature and the GAA concentration. The packaging material was delaminated under conditions of $60{ }^{\circ} \mathrm{C}, 70 \mathrm{v} \%$ GAA solution, liquid/solid ratio $20: 1$ and delamination time $60 \mathrm{~min}$, and separation of polyethylene, paper and aluminum foil was conducted through sink-float method and air separation. Polyethylene, paper and aluminum foil were separated efficiently. The recovery and purity of aluminum foil was $90.81 \%$ and $100 \%$, respectively; the purity of polyethylene was $100 \%$; the recovery and purity of paper was $100 \%$ and $96.03 \%$, respectively. This study offers some technical insights for recycling of aluminum-plastic packaging.
\end{abstract}

Keywords: Delamination, separation, aluminum, polyethylene, packaging material.

\section{INTRODUCTION}

Aluminum-plastic-paper material is widely used as packaging material owing to its light resistance, hygiene and low-cost [1], replacing many other materials, e.g. glass as containers for liquid foods. Paper gives strength to the packages, and the plastics ensure a tight seal. Polyethylene (PE) is the most common polymer used in food packaging and has excellent sealing properties and relatively low cost [2]. Aluminum foil is employed due to the poor barrier properties of PE for oxygen.

Wastes of aluminum-plastic-paper materials are constantly increasing due to the mass production and consumption [3]. The 2011 sustainable report of Tetra Pak shows that the the number of Tetra Pak packages is up to 158 billions while the recovery rate is only $20.1 \%$ in 2010. Since waste packages cause environmental pollution and waste of resources, and the growth of wastes has a great impact on their management.

Recycling allows the materials containing aluminum, high quality fibers and plastics to be reused, reducing disposal problem and increasing economic and social benefits [1]. Recycling of aluminum-plastic packaging materials receives increasing attention [3-6], and numerous techniques were developed such as separation with solvent [7-9], electrical separation [10]

${ }^{*}$ Address correspondence to this author at the School of Chemistry and Chemical Engineering, Key Laboratory of Resources Chemistry of Nonferrous Metals, Ministry of Education, Central South University, Changsha, 410083 Hunan, China; Tel: +86-731-88879616; E-mail: huiwang1968@163.com and argon electrolysis [11]. Separation of packaging materials can be achieved through soaking in acid or base solutions $[3,8]$. Strong acid or strong base solutions can react with aluminum in the materials, and thus plastics are separated; weak acid solutions react with aluminum oxide that is between polyethylene and aluminum foil, and thus polyethylene and aluminum foil are delaminated [12]. In our study, delamination aluminum-polyethylene-paper packaging materials was studied, and separation of the delaminated products was further conducted through air separation and sinkfloat method. The separated PE was identified by Fourier transform infrared spectrum.

\section{MATERIALS AND METHODS}

\subsection{Materials}

The samples of packaging material were from Tetra Pak, which was a laminate of low-density polyethylene (LDPE), paper and aluminum foil. The intersecting surface of packaging material can be shown as Figure 1 , and the content of paper, LDPE and aluminum foil in the material was $75 \%, 20 \%$ and $5 \%$, respectively [13]. Glacial acetic acid (GAA), analytically pure, was used to delaminate the laminated packaging material.

\subsection{Delamination and Separation of the Packaging Material}

The packaging material was cut into pieces of $1 \mathrm{~cm} \times 1 \mathrm{~cm}$, and it was delaminated in $100 \mathrm{~mL}$ conical flask with GAA solution. GAA solutions with different concentration were prepared by mixing $100 \mathrm{~mL}$ GAA with certain volume of distilled water. The delamination 
experiments were conducted in a thermostat-controlled (DF-101S, Shanghai Bilon Instruments Co., LTD, China) water bath, and, after a given time, the conical flask was taken out. In orthogonal experiments, liquid/solid ratio was also studied, which was conducted by adding a certain amount of packaging material into a certain volume of GAA solution. The average value of delamination time was obtained from three tests.

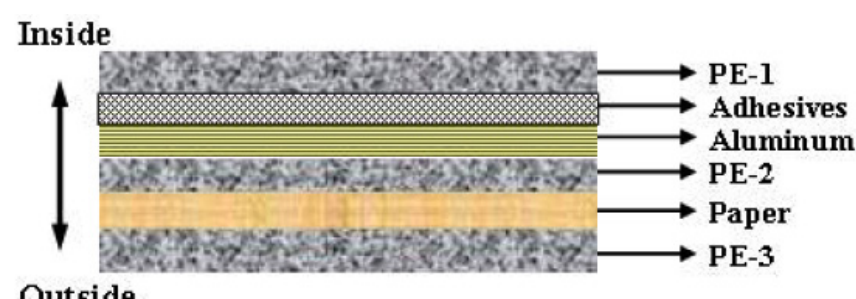

\section{Outside}

Figure 1: Schematic diagram of aluminum-polyethylenepaper packaging material.

After delamination of the packaging material with GAA, separation of the delaminated materials was further conducted. The delaminated PE was first separated by sink-float method, which was carried out by mixing the delaminated materials with tap water; after draining off, air separation was conducted to separate aluminum foil using the air separation column; the left materials were further soaked in GAA solution, and PE was separated from paper through sink-float method.

\section{RESULTS AND DISCUSSION}

\section{1. $L_{9}\left(3^{4}\right)$ Orthogonal Experiments}

The factors of temperature (A), GAA concentrations (B) and liquid/solid ratio (C) were investigated by orthogonal experiment of three factors and three levels, and the tests were performed without agitation. The variable assignment and the level settings are shown in Table 1. The results of $L_{9}\left(3^{4}\right)$ orthogonal experiments are presented in Table $2 . \mathrm{K}_{1}, \mathrm{~K}_{2}$ and $\mathrm{K}_{3}$ represent the sum of leaching rate of $\mathrm{Al}$ of level 1 , level 2 and level 3 of a factor, respectively. $\mathrm{K}_{1} / 3, \mathrm{~K}_{2} / 3$ and $\mathrm{K}_{3} / 3$ represent

Table 1: Experimental Factors and Levels

\begin{tabular}{|c|c|c|c|}
\hline \multirow{2}{*}{ Level } & \multicolumn{3}{|c|}{ Factor } \\
\hline & $\mathrm{A}\left({ }^{\circ} \mathrm{C}\right)$ & B (v\%) & $C(\mathrm{~mL} / \mathrm{g})$ \\
\hline 1 & 30 & 20 & 15 \\
\hline 2 & 40 & 40 & 25 \\
\hline 3 & 50 & 60 & 35 \\
\hline
\end{tabular}

the average of $\mathrm{K}_{1}, \mathrm{~K}_{2}$ and $\mathrm{K}_{3}$, respectively. $\mathrm{R}$ denotes the maximum difference value among $\mathrm{K}_{1}, \mathrm{~K}_{2}$ and $\mathrm{K}_{3}$.

Table 2: The Results of $L_{9}\left(3^{4}\right)$ Orthogonal Experiments

\begin{tabular}{|c|c|c|c|c|}
\hline \multirow{2}{*}{} & \multicolumn{3}{|c|}{ Factor } \\
\cline { 2 - 5 } & A ( $\left.{ }^{\circ} \mathrm{C}\right)$ & $\mathbf{B}(\mathbf{v} \%)$ & $\mathbf{C}(\mathbf{m L} / \mathbf{g})$ & $\begin{array}{c}\text { Delamination time } \\
\text { (min) }\end{array}$ \\
\hline \hline 1 & 1 & 1 & 1 & 4.9 \\
\hline 2 & 1 & 2 & 2 & 2.5 \\
\hline 3 & 1 & 3 & 3 & 1.8 \\
\hline 4 & 2 & 1 & 2 & 3.6 \\
\hline 5 & 2 & 2 & 3 & 1.25 \\
\hline 6 & 2 & 3 & 1 & 0.95 \\
\hline 7 & 3 & 1 & 3 & 3.2 \\
\hline 8 & 3 & 2 & 1 & 1.1 \\
\hline 9 & 3 & 3 & 2 & 0.25 \\
\hline $\mathrm{K}_{1}$ & 9.2 & 11.7 & 6.95 & \\
\hline $\mathrm{K}_{2}$ & 5.8 & 4.85 & 6.35 & \\
\hline $\mathrm{K}_{3}$ & 4.55 & 3 & 6.25 & \\
\hline $\mathrm{K}_{1} / 3$ & 3.07 & 3.90 & 2.32 & \\
\hline $\mathrm{K}_{2} / 3$ & 1.93 & 1.62 & 2.12 & \\
\hline $\mathrm{K}_{3} / 3$ & 1.52 & 1.00 & 2.08 & \\
\hline $\mathrm{R}$ & 1.55 & 2.90 & 0.23 & \\
\hline & & & & \\
\hline
\end{tabular}

As demonstrated in Table 2, the most significant factor is GAA concentration followed by temperature and liquid/solid ratio. The optimal scheme is $A_{3} B_{3} C_{3}$; the experimental conditions are $50{ }^{\circ} \mathrm{C}, 60 \mathrm{v} \%$ and liquid/solid ratio 35:1. In order to prove the optimized scheme, leaching tests were conducted under condition of temperature $\left(50{ }^{\circ} \mathrm{C}\right)$, GAA concentration (60 $\mathrm{v} \%$ ) and liquid/solid ratio (35:1), and delamination time was $10 \mathrm{~min}$, which is in agreement with the result from orthogonal experiments.

The GAA solution reacts with $\mathrm{Al}_{2} \mathrm{O}_{3}$ located on the surface of aluminum foil. The GAA ionizes first, and then the aluminium oxide is dissolved. The action mechanism of GAA can be explained by the Equation (1) [12]. The GAA concentration dominates mainly the reaction rate, and temperature has significant effect on the reaction.

$\mathrm{CH}_{3} \mathrm{COOH} \rightarrow \mathrm{H}^{+}+\mathrm{CH}_{3} \mathrm{COO}^{-}$

$6 \mathrm{H}^{+}+\mathrm{Al}_{2} \mathrm{O}_{3} \rightarrow 2 \mathrm{Al}^{3+}+3 \mathrm{H}_{2} \mathrm{O}$ 


\subsection{Effect of GAA Concentration on Delamination Time}

The samples of the packaging material were delaminated in GAA solution at $60{ }^{\circ} \mathrm{C}$ to investigate the effect of concentration of GAA on delamination time, and the result is shown in Figure 2.

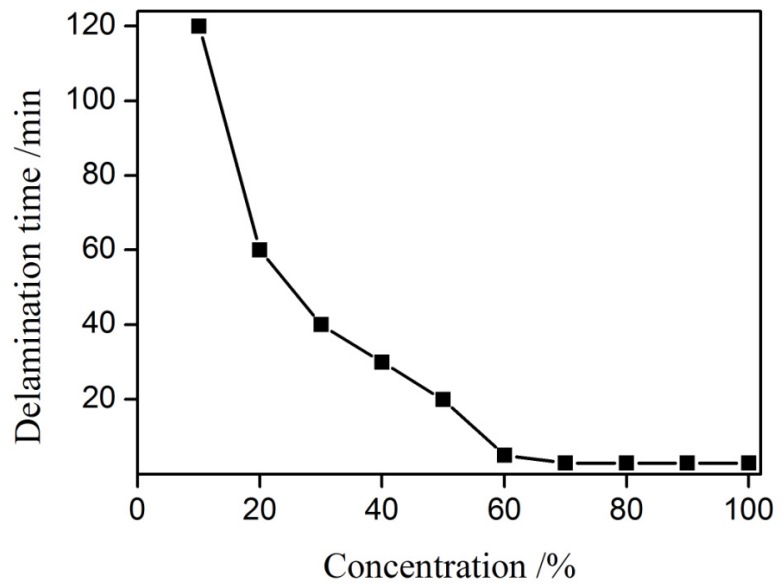

Figure 2: Delamination time as a function of GAA concentration $\left(60{ }^{\circ} \mathrm{C}\right.$, liquid/solid ratio $\left.20: 1\right)$.

As shown in Figure 2, the delamination time was 120 min when the concentration of GAA was $10 \mathrm{v} \%$, and the delamination time decreased sharply with increasing the concentration of GAA. The delamination time was reduced to $5 \mathrm{~min}$ when the concentration of GAA was $60 \mathrm{v} \%$, and the delamination time dropped very slightly with further increasing the concentration of GAA. Considering the high concentration of GAA was easily volatile, the proper concentration of GAA was 70 $\mathrm{v} \%$.

The delamination is the result of reactions between GAA and aluminum oxide. At lower concentration, the reaction rate rests on the ionization of GAA, which provides enough $\mathrm{H}^{+}$for delamination reaction. When the concentration is above $60 \mathrm{v} \%$, the reaction rate is dominated by other factors such as temperature and the liquid/solid ratio.

\subsection{Effect of Temperature on Delamination Time}

Delamination of the samples of the packaging material was conducted in GAA solution at different temperature to investigate the effect of temperature on delamination time, and the result is shown in Figure 3. Temperature has significant impact on delamination time; the delamination time reduces remarkably with increasing temperature. Increasing temperature results in a decrease of reaction rate, and temperature is the governing factor of delamination reaction at temperature above $60{ }^{\circ} \mathrm{C}$. When the concentration of GAA is $60 v \%, 70 v \%$ and $80 v \%$, the delamination time at $60{ }^{\circ} \mathrm{C}$ is $5 \mathrm{~min}, 3 \mathrm{~min}$ and $3 \mathrm{~min}$, respectively. When the temperature is higher than $60{ }^{\circ} \mathrm{C}$, the delamination time remains steady. The higher temperature promotes the volatilization of GAA, and thus the applicable temperature is $60{ }^{\circ} \mathrm{C}$.

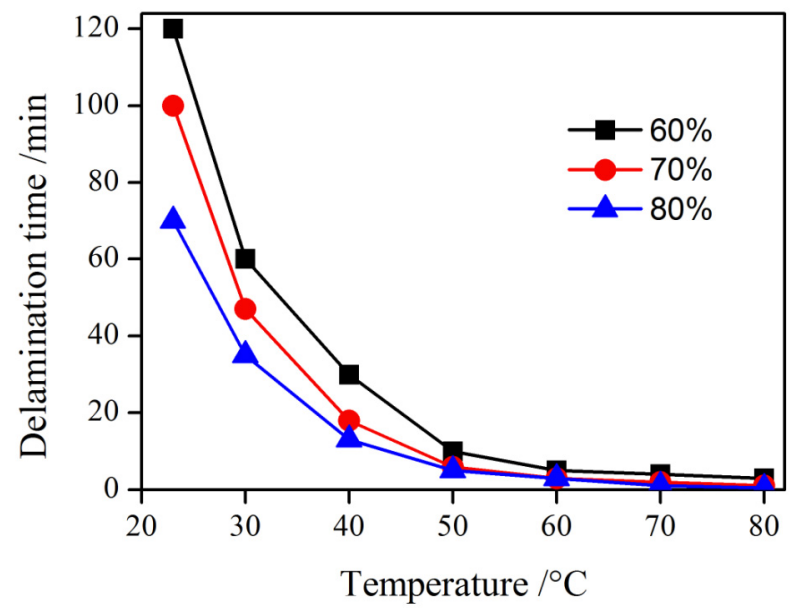

Figure 3: Delamination time as a function of temperature (liquid/solid ratio 20:1).

\subsection{Effect of Liquid/Solid Ratio on Delamination Time}

Delamination time as a function of liquid/solid ratio is shown in Figure 4. It can be seen that delamination time decreases with an increase of liquid/solid ratio, the time reduces remarkably from $41 \mathrm{~min}$ to $27 \mathrm{~min}$ when the ratio increases from 10 to 25 , and it drops slightly with further increasing of the ratio. From Figure 4, it can be concluded that liquid/solid ratio of above 20 is practicable for delamination of the packaging material.

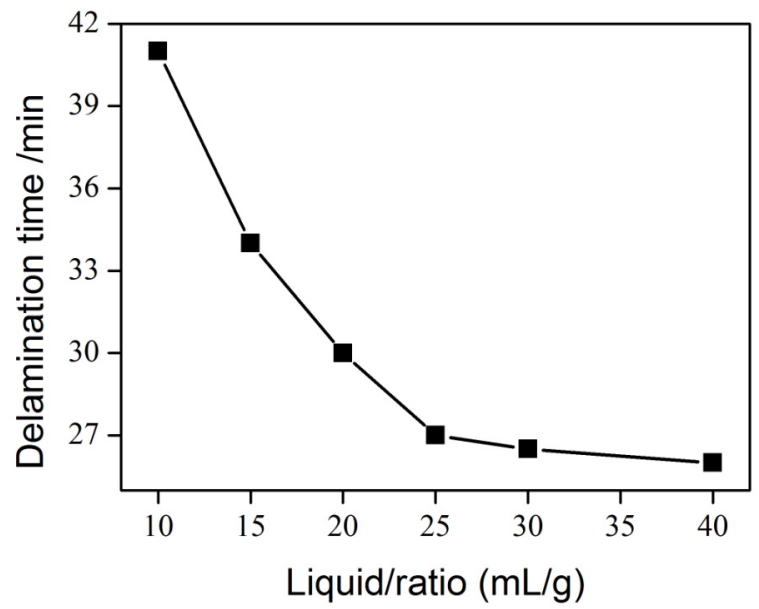

Figure 4: Delamination time as a function of liquid/ratio (60 ${ }^{\circ} \mathrm{C}, 40 \mathrm{v} \%$ ). 
Packaging Materials

(Aluminum, Plastic, Paper)

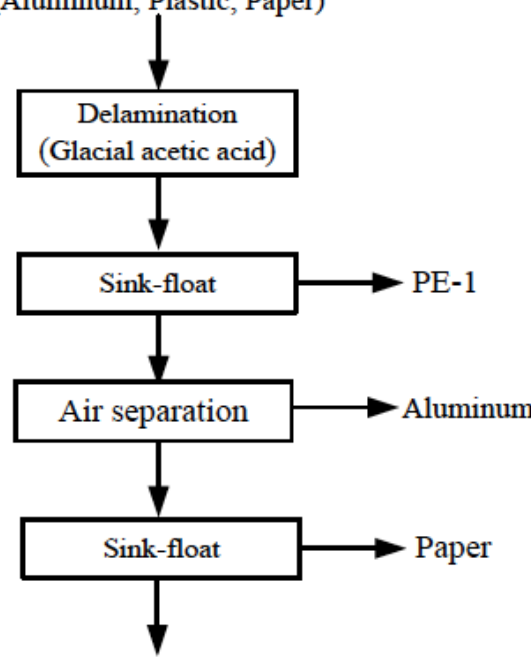

PE-2, PE-3

Figure 5: The flow sheet of separation of the packaging materials.

\subsection{Separation of the Delaminated Materials}

The packaging material was delaminated under conditions of $60{ }^{\circ} \mathrm{C}, 70 \mathrm{v} \%$ GAA solution, liquid/solid ratio $20: 1$ and delamination time $60 \mathrm{~min}$. After filtration, the sink-float was conducted with water as medium,

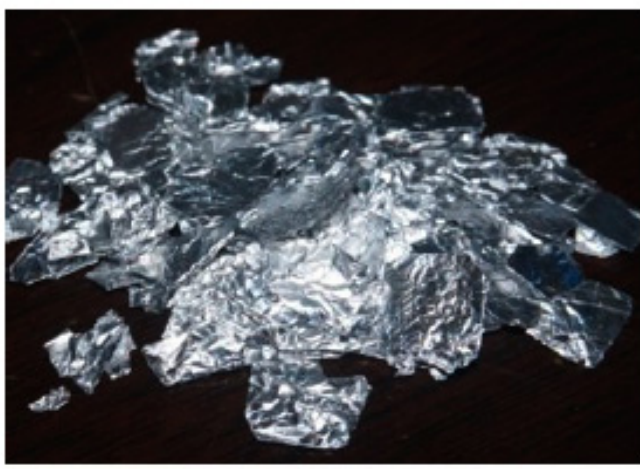

(a) Aluminum foil

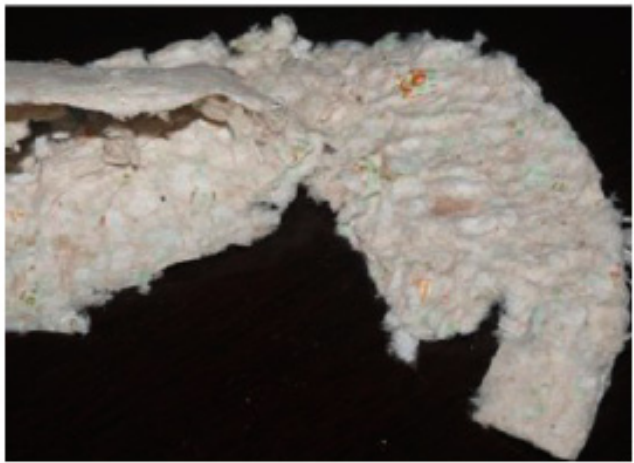

(c) PaPer
Table 3: Separation Result of the Packaging Materials

\begin{tabular}{|c|c|c|}
\hline Materials & Recovery (\%) & Purity (\%) \\
\hline \hline Aluminum foil & 90.81 & 100 \\
\hline PE-1 & 95.45 & \multirow{2}{*}{100} \\
\hline PE-2 & 100 & \\
\hline PE-3 & 100 & 96.03 \\
\hline Paper & 100 & \\
\hline
\end{tabular}

and the PE-1 was obtained. The left materials were drained off and separated using air separation, and the aluminum foil was separated. The left paper and PE were further soaked in $60 \%$ GAA solution for $30 \mathrm{~min}$ with stirring rate of $20 \mathrm{rpm}$. After filtration, the sink-float was conducted with water as medium to separate paper and PE. The flow sheet of separation of the packaging materials is shown as Figure $\mathbf{5}$, and the result is displayed in Table 3.

As demonstrated in Table 3, the recovery and purity of aluminum foil is $90.81 \%$ and $100 \%$. The purity of $\mathrm{PE}$ is $100 \%$, and a small quantity of PE-1 was left in paper. The recovery and purity of paper is $100 \%$ and $96.03 \%$, and the paper was contaminated with a small amount of $\mathrm{PE}$ and aluminum foil.

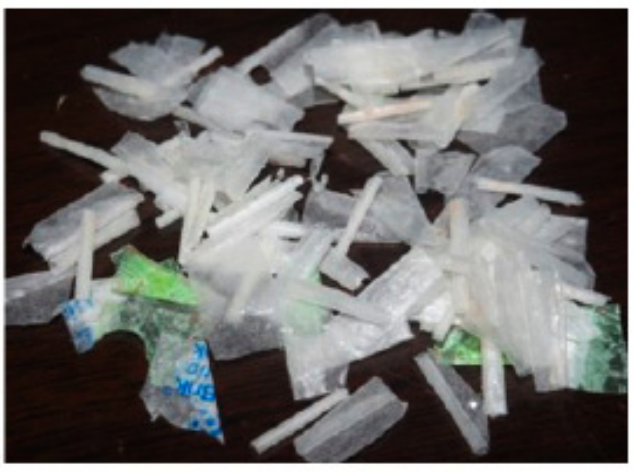

(b) PE-2, PE-3

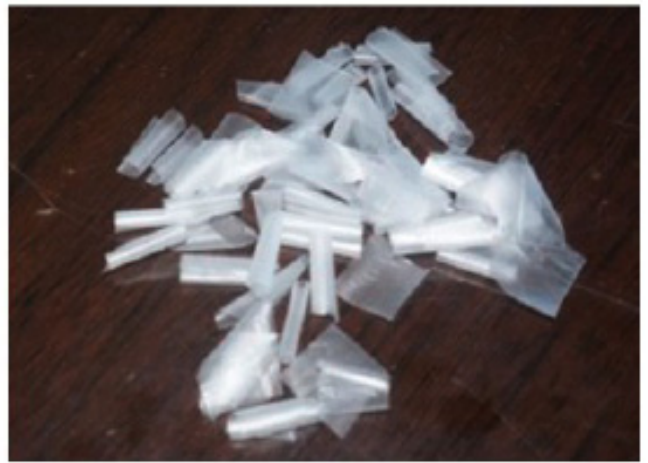

(d) PE-1

Figure 6: The pictures of separated products. 
The separated products are shown in Figure 6. It can be seen that aluminum is separated from paper and PE plastic, and pure aluminum is obtained. PE-1 located inside of the packaging material is separated partly with little contamination, while PE-3 located outside of the material is contaminated with a little paper and printing ink. In separation process, paper pulp is achieved and can be used for paper recycling directly, and Figure $6 \mathrm{c}$ shows the dried paper. The separated aluminum, PE-1 and paper are of high purity and can be utilized to produce high quality products.

The separated PE-1 was identified by Fourier transform infrared (Figure 7). As shown in Figure 7, spectrum of PE shows typical molecular vibrations at $2916 \mathrm{~cm}^{-1}, 2850 \mathrm{~cm}^{-1}, 1470 \mathrm{~cm}^{-1}$ and $723 \mathrm{~cm}^{-1}$. Thereinto, molecular vibrations at $2916 \mathrm{~cm}^{-1}$ and 2850 $\mathrm{cm}^{-1}$ result from the asymmetric and symmetric stretching vibrations of methylene $\left(-\mathrm{CH}_{2}\right)$; the absorption peak at $1470 \mathrm{~cm}^{-1}$ is attributed to -C-Cbonds; molecular vibration at $723 \mathrm{~cm}^{-1}$ is rotational absorption peak of methylene $\left(-\mathrm{CH}_{2}\right)$ [14]. The strong absorption intensity is owing to that the tested PE film is thick. Fourier transform infrared spectrum of the separated PE verifies that purified PE is recovered effectively.

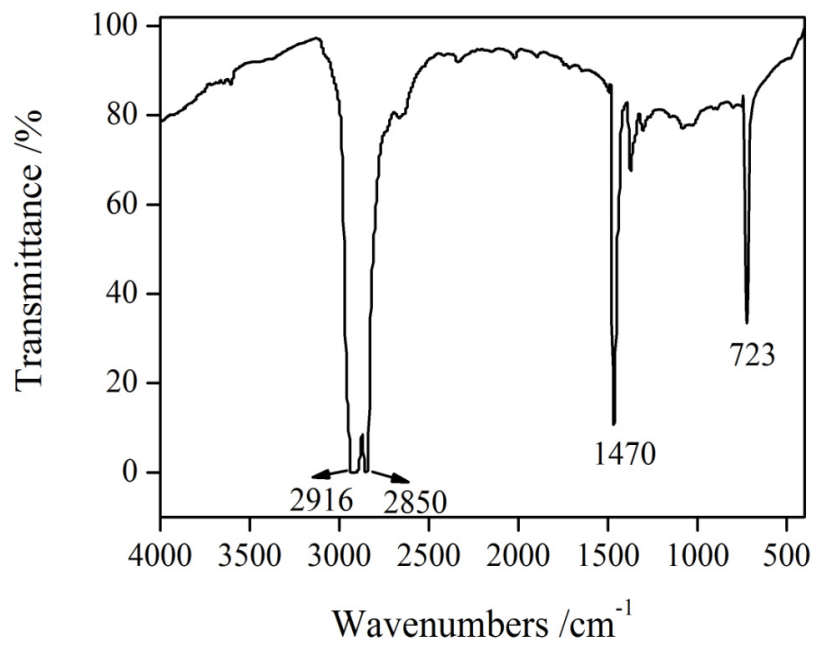

Figure 7: Fourier transform infrared spectrum of PE.

This experimental finding leads to an environmentally friendly method for the effective material cycling of large quantity of aluminum-plastic packaging. The GAA solution is cheap, and its recycling is available. The process is simple, and the delaminated products are recovered with high purity. Applications of this technology in the industry could have great potential economically and environmentally.

\section{CONCLUSIONS}

The orthogonal design was employed to investigate the effects of temperature, GAA concentration and liquid/solid ratio on delamination time. The $L_{9}\left(3^{4}\right)$ orthogonal experiments indicate the most significant factor is GAA concentration followed by temperature and liquid/solid ratio. Under the optimal experimental conditions of temperature $\left(50{ }^{\circ} \mathrm{C}\right)$, GAA concentration $(60 \mathrm{v} \%)$ and liquid/solid ratio (35:1), and delamination time was $10 \mathrm{~min}$

The delamination time decreased sharply with increasing of GAA concentration, temperature and liquid/solid ratio. The proper GAA concentration of was $70 \mathrm{v} \%$, the optimal temperature was $60{ }^{\circ} \mathrm{C}$ and the practicable liquid/solid ratio is above 20 .

The packaging material was delaminated under conditions of $60{ }^{\circ} \mathrm{C}, 70 \mathrm{v} \%$ GAA solution, liquid/solid ratio $20: 1$ and delamination time $60 \mathrm{~min}$, and separation of polyethylene, paper and aluminum foil was conducted through sink-float method and air separation. Polyethylene, paper and aluminum foil were separated efficiently. The recovery and purity of aluminum foil was $90.81 \%$ and $100 \%$, respectively; the purity of PE was $100 \%$; the recovery and purity of paper was $100 \%$ and $96.03 \%$, respectively. This study offers some technical insights for recycling of aluminum-plastic packaging.

\section{ACKNOWLEDGEMENT}

This study was supported by the Fundamental Research Funds for the Central Universities of Central South University.

\section{REFERENCES}

[1] Chongchen W, Peng W. Recovery and reuse technology of polyethylene-aluminum composite packing materials. J Beijing Inst Civil Eng Archit 2005; 21(4): 63-64 (In Chinese)

Olafsson G, Jägerstad M, Öste R, Wesslén B. Delamination of polyethylene and aluminum foil layers of laminated packaging material by acetic acid. J Food Sci 1993; 58(1): 215-19.

http://dx.doi.org/10.1111/j.1365-2621.1993.tb03248.x

[3] Sufeng Z, Xingxian M, Lulu Z. Research progress of separation technology of aluminum-plastic in aseptic composite packaging. China Pulp Paper 2012; 31(2): 65-65 (In Chinese).

[4] Fangjuan F, Zhongping Y, Fuxi S, Discussion on recovery and reuse of Tetra Pak package. J Agric Mechan Res 2007; 9(4): 221-21 (In Chinese)

[5] Hidalgo $M$. Manufacturing rigid board by packaging waste containing aluminum and polyethylene. J Scient Ind Res 2011; 70(3): 232-34 
[6] Murathan A, Murathan AS, Gürü $M$, Balbaşı $M$. Manufacturing low density boards from waste cardboards containing aluminium. Materials Design 2007; 28(7): 221517.

http://dx.doi.org/10.1016/j.matdes.2006.06.014

[7] Sufeng Z, Lulu Z, Xingxian M Research on aluminum-plastic separation process with benzyl alcohol-water method. China Pulp Paper Industry 2011; 32(20): 43-46 (In Chinese).

[8] Guo-Hua G, Bo Z. Study on the separation between aluminum and plastic in scraps of plastic containing aluminum. Mining Metallurgical Eng 2007; 27(5): 47-50.

[9] Kulkarni AK, Daneshvarhosseini S, Yoshida H. Effective recovery of pure aluminum from waste composite laminates by sub-and super-critical water. J Supercritical Fluids 2011; 55(3): 992-97. http://dx.doi.org/10.1016/j.supflu.2010.09.007

[10] Gente V, La Marca F, Lucci F, Massacci P. Electrical separation of plastics coming from special waste. Waste Management 2003; 23(10): 951-58.

http://dx.doi.org/10.1016/S0956-053X(03)00088-6
[11] Lopes CMA, Felisberti MI. Composite of low-density polyethylene and aluminum obtained from the recycling of postconsumer aseptic packaging. J Appl Polym Sci 2006; 101(5): 3183-91.

http://dx.doi.org/10.1002/app.23406

[12] Yifei Z, Dahai Y, Li L, Ziliang Y, Zhonghe L. Research on the effect of separation reagent concentration and reaction temperature on Al-PE wet separation techniques. Chin J Environ Eng 2010; 4(3): 665-670 (In Chinese).

[13] Żukowski W, Baron J, Zabagło J, Kandefer S, Olek M. Recovery of aluminium from multi-component packaging using a fluidised bed reactor. Polish J Chem Technol 2008; 10(4): 40-44. http://dx.doi.org/10.2478/v10026-008-0046-y

[14] Huacai C, Rapid discrimination of polyethylene (PE) and polyvinyl chloride (PVC) food wrapping film by infrared spectroscopy. J China Jiliang Univ 2005; 16(4): 299-301 (In Chinese). 